\title{
A polydrug regime for treatment of sudden sensorineural hearing loss
}

\author{
Muniraju M., Shambulinga Killera, Safina Kauser*
}

Department of ENT, Dr. B. R. Ambedkar Medical College and Hospital, Bangalore, Karnataka, India

Received: 21 August 2020

Revised: 02 October 2020

Accepted: 31 October 2020

\author{
*Correspondence: \\ Dr. Safina Kauser, \\ E-mail: safina820@gmail.com
}

Copyright: (c) the author(s), publisher and licensee Medip Academy. This is an open-access article distributed under the terms of the Creative Commons Attribution Non-Commercial License, which permits unrestricted non-commercial use, distribution, and reproduction in any medium, provided the original work is properly cited.

\begin{abstract}
Sudden sensorineural hearing loss (SSNHL) is a very frightening and incapacitating event and it impairs the patient's quality of life. Steroids are considered the first line of treatment. Intratympanic dexamethasone produces a significantly higher perilymph concentration of steroids. The aim of our study was to assess the efficacy of multi-drug regimen in the management of SSNHL, to analyse the recovery and to assess use of intratympanic steroid injections (ITSI) as a primary treatment. This is a prospective study presenting as a case series of 5 cases of SSNHL. Our treatment included intratympanic steroids, oral steroids, antiplatelet drugs, rheological-agents and neuro vitamins. Complete recovery was seen in $2(40 \%)$, partial recovery in $2(40 \%), 1$ patient was lost to follow up. In the patient with bilateral SSNHL, the ITSI was administered in the right ear only; which showed a significant improvement. SSNHL is described as a decline in hearing of $30 \mathrm{~dB}$ or more, on 3 or more frequencies over 3 days or less, with tinnitus and ear fullness. Early presentation and intervention within 72 hours is the ideal treatment. Since viral infections and vascular compromise are considered as probable theories for SSNHL, steroids, with anticoagulants, antiplatelet and rheological-agents are used as an effective therapy. Our study shows that a multi-drug treatment of SSNHL can be much more effective than a single drug treatment. We also conclude that using intratympanic steroid injections have a greater improvement as seen in the case of bilateral SSNHL.
\end{abstract}

Keywords: SSNHL, ITSI, Recovery, Pure tone audiometry

\section{INTRODUCTION}

SSNHL is described as a decline in hearing of $30 \mathrm{~dB}$ or more, on 3 or more frequencies over 3 days or less, with tinnitus and ear fullness. ${ }^{1}$ The incidence varies from 2 to 30 per 1,00,000 adult individuals and there is no gender predilection. $^{2}$ The overall incidence is mostly underestimated. ${ }^{3}$ SSNHL accounts for approximately $1 \%$ of all cases of sensorineural hearing loss. Hearing loss is usually unilateral and accompanied by tinnitus (70\%), vertigo or sensation of spatial disorientation $(50 \%){ }^{4}$

Causes include viral or bacterial infection, disruption of cochlear membranes, vascular compromise, drug toxicity and autoimmune mediated diseases. Prognosis depends on various factors like age, time of reporting and diagnosis, treatment delay time, comorbidities, severity of hearing loss, unilateral or bilateral hearing loss, associated tinnitus or vertigo. ${ }^{5}$ Lack of knowledge of specific cause of SSNHL limits the use of effective treatment. ${ }^{6}$

Numerous drugs have been tested in an attempt to improve the outcome in patients presenting with SSNHL. ${ }^{7}$ Steroids are considered the first line of treatment. ITSI can be used as primary, adjuvant or salvage therapy. ${ }^{2}$ Intratympanic dexamethasone produces significantly higher perilymph concentrations of steroids than does intravenous or oral administration. ${ }^{8}$ Here, in our study we recommend primary use of ITSI. 


\section{CASE SERIES}

This is a small prospective study presenting as a case series. We included 5 cases of sudden sensorineural hearing loss which met the following criteria of SSNHL of at least $30 \mathrm{~dB}$ HL, SSNHL of unknown etiology, patient reporting within 72 hours, no past otological history in that ear, not on any treatment for the present condition. This study was aimed to assess efficacy of multi-drug regimen in the management of SSNHL, to analyse the outcome of recovery and to assess use of ITSI as a primary treatment.

\section{Clinical evaluation}

A detailed history of hearing loss was taken from the 5 patients and any history of associated tinnitus, vertigo, focal neurological signs was also enquired. A thorough otoscopic and microscopic examination was done of both the ears to rule out other causes. This was followed by an audiometric evaluation.

\section{Audiometric evaluation}

Pure tone audiometry (PTA) was calculated as an average of thresholds measured at 250, 500, 1000, 2000, 4000, $8000 \mathrm{~Hz}$. Initial hearing loss level categorised as mild, moderate, moderately severe, severe and profound hearing loss. The audiometric shape was also noted as upward or ascending curve, downward or descending curve and flat type.

\section{Standard treatment}

All patients were given the following medications:

\section{ITSI}

Intratympanic dexamethasone injections were given in a dose of $0.5 \mathrm{ml}(4 \mathrm{mg} / \mathrm{ml})$ for 5 sittings, starting on the day of presentation (day 0) followed by on day 3, 6, 9 and 12 .

\section{Technique}

In supine position with head turned to the other side, a thorough endoscopic or microscopic examination and confirmation of an intact tympanic membrane was done and topical anaesthesia (4\% lignocaine) was given. Using a $26 \mathrm{G}$ spinal needle, a small puncture was made in the antero-superior or postero-inferior quadrant for ventilation and an antero-inferior puncture was made for delivery of dexamethasone (Figure 1). No myringotomy or ventilation tube insertion done. Patient was instructed to avoid swallowing or moving the head for about 30 mins.

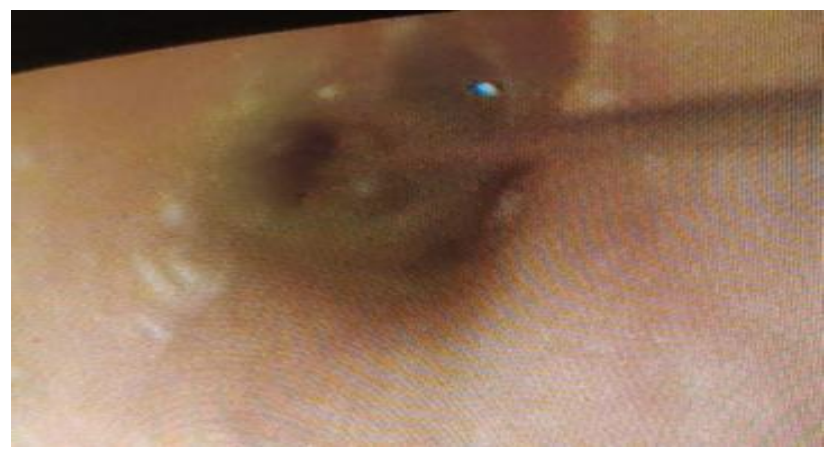

Figure 1: Technique of ITSI.

\section{Oral steroids}

Tablet prednisolone was given as a standard dosage of 30 $\mathrm{mg} /$ day in 3 divided dosage for 5 days followed by a tapering dosage of $20 \mathrm{mg} /$ day BD for 5 days, then $10 \mathrm{mg}$ OD for 5 days.

\section{Neuroprotective drugs}

Neuro vitamins given OD for 15 days.

\section{Rheological agents}

Tablet pentoxifylline $400 \mathrm{mg}$ was given OD for 15 days.

Antiplatelet drugs

Tab clopidogrel $75 \mathrm{mg}$ was given OD for 15 days.

\section{Measurement of outcome}

PTA was performed on day 15 (after 5 doses of ITSI).

\section{According to Seigel's hearing recovery criteria}

The following recovery criteria were used-complete recovery: final hearing better than $25 \mathrm{~dB}$, partial recovery: final hearing between $25-45 \mathrm{~dB}$ (or $15 \mathrm{~dB}$ gain), slight improvement: final hearing $<45 \mathrm{~dB}(>15 \mathrm{~dB}$ gain), no improvement: final hearing $<75 \mathrm{~dB}(<15 \mathrm{~dB}$ gain).

Table 1: Patient details.

\begin{tabular}{|lllllll|}
$\begin{array}{l}\text { Age/sex } \\
\text { (year) }\end{array}$ & $\begin{array}{l}\text { Pre-PTA } \\
\text { Right }\end{array}$ & Left & Degree of hearing loss & Type of curve & $\begin{array}{l}\text { Post-PTA } \\
\text { Right }\end{array}$ & \multicolumn{1}{c|}{ Left } \\
\hline 44/F & 15 & 70 & L-moderately severe SNHL & Downward sloping & 15 & 40 \\
\hline 40/M & 21.6 & 71.6 & L-severe SNHL & Flat curve & 16.6 & 21.6 \\
\hline 26/M & 45 & 16.6 & R-moderate SNHL & Upward sloping & Lost to follow up \\
\hline 62/M & 63.3 & 53.3 & R-moderately severe SNHL & Flat curve & 33 & 50 \\
\hline
\end{tabular}




\begin{tabular}{|lllllll|}
$\begin{array}{l}\text { Age/sex } \\
\text { (year) }\end{array}$ & $\begin{array}{l}\text { Pre-PTA } \\
\text { Right }\end{array}$ & Left & Degree of hearing loss & Type of curve & $\begin{array}{l}\text { Post-PTA } \\
\text { Right }\end{array}$ & Left \\
\hline $\mathbf{5 0} / \mathbf{M}$ & 72 & 15 & R-severe SNHL & Flat curve & 24 & 15 \\
\hline
\end{tabular}

There were 1 female and 4 males. The right and left ears were affected in 2 patients each (Table 1). One had bilateral SSNHL. One patient had diabetes mellitus as a comorbidity and was lost to follow up after day 3 . All the patients complained of concomitant onset of tinnitus with hearing loss.

According to the level of initial hearing loss, patients were divided into four classes of hearing loss: Moderate hearing loss (1) moderate-severe hearing loss (2), severe hearing loss (2) and profound hearing loss (0). Types of hearing loss pattern in pure tone audiogram were observed as ascending (1), descending (1), and flat type (3).

Figure 2 shows one of the pre and post PTA plotting charts (Figure 2). The pre-treatment and post-treatment results have been shown below (Figure 3).

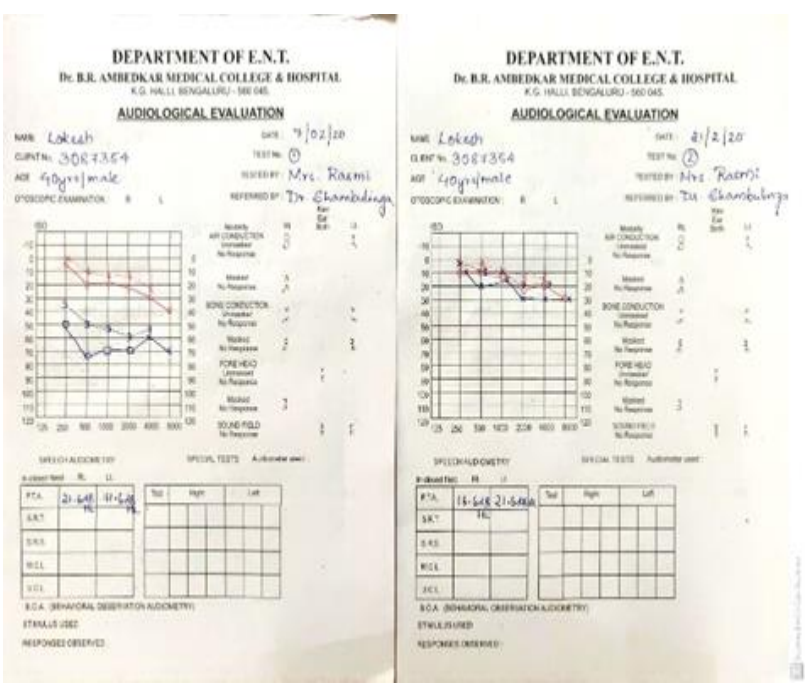

Figure 1: Pre and post PTA plotting graph.

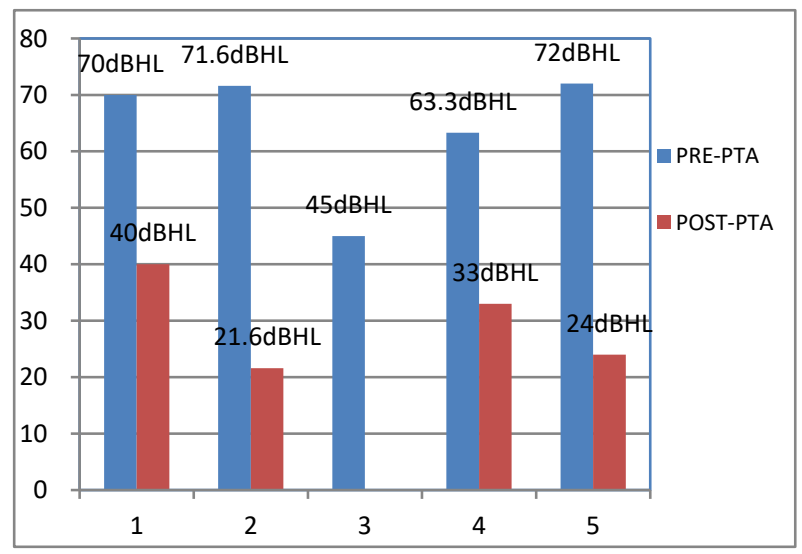

Figure 3: Pre and post PTA results.
According to the classification for extent of recovery as per Seigel's criteria; complete recovery (type 1) was seen in $2(40 \%)$, partial recovery (type 2) was seen in $2(40 \%)$ and 1 patient who was lost to follow up (Figure 4 ).

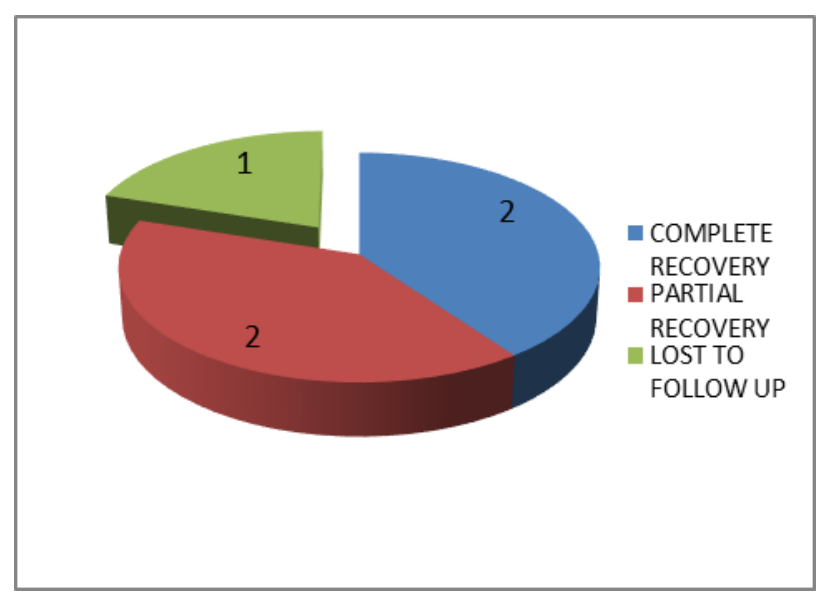

Figure 4: Recovery according to Seigel's criteria.

For the purpose of statistical analysis, complete recovery and partial recovery are combined in recovery group. $100 \%$ of the treated patients got improvement. In the patient with bilateral sudden sensorineural hearing loss, the ITSI was administered in the right ear only which showed a significant improvement, which implies that though the adjuvant treatment and oral steroids are helpful in treating SSNHL, ITSI can be considered as the mainstay of treatment.

\section{DISCUSSION}

Steroid therapy is the mainstay of treatment for SSNHL. Steroids have been shown to have anti-inflammatory properties, antioxidant activity, role in ion haemostasis, inhibition of apoptosis, increasing the cochlear blood flow, improve stria vascularis function and maintain the endocochlear potential. ${ }^{1}$ Other treatment options are vasodilator and vasoactive substances including carbogen therapy, calcium channel blockers, pentoxifylline; antioxidants, histamines, minerals, vitamins, diuretics, herbal remedies and hyperbaric oxygen therapy. ${ }^{2}$

SSNHL is an otological emergency. A wide spectrum of etiology is proposed for SSNHL, including local and systemic diseases like viral infections, temporary breaks in the inner ear membrane and immune mediated reactions. Common systemic disease such as diabetes mellitus and hypertension may affect the recovery in patients by virtue of associated microangiopathy. ${ }^{3}$ This could be considered as a reason that one patient did not follow up due to no improvement in symptoms. 
Since viral infections and vascular compromise are considered as probable theories for SSNHL, antiviral agents, anticoagulants, and stellate ganglion blockers have been used for its treatment. ${ }^{6}$ Proposed theories of pathogenesis of idiopathic SSNHL include viral cochleitis, vascular occlusion and membrane breaks. ${ }^{7}$ Though studies have shown no statistical improvement with the use of antivirals. However, Anticoagulants, antiplatelet and rheological agents are used as an effective adjuvant therapy. SSNHL is a very frightening and incapacitating event and it impairs the patient's quality of life and also their social interaction. ${ }^{8}$ Mechanism behind SSNHL is considered multifactorial and the data suggests involvement of immunomodulatory cells, increased concentration of pro-inflammatory cytokines in inner ear and TNF-alpha triggering ischemic microvascular events. ${ }^{9}$

Intratympanic route of steroid administration to the inner ear for treatment of SSNHL is a better techniqueallowing the delivery of small amounts of steroids, with the advantage of direct uptake through the round window membrane, bypassing the adverse events of systemic route and simultaneously allowing for a higher steroid concentration in perilymphatic fluid. ${ }^{5,9}$

The average age of onset in our study is 44 years, which is similar to a study by Byl et al, where the mean age was 46-49 years. ${ }^{10}$ All our patients presented within 72 hours of the symptoms and it has been concluded by Bullo et al that delay in starting treatment is considered as a poor prognostic factor. ${ }^{11}$ In a study by Battaglia et al, they conclude that combined ITSI and oral steroid therapy is superior to oral therapy alone. ${ }^{12}$ Which we also conclude. However there have been no significant studies reporting the use of antiplatelets, rheological agents and neuroprotective. According to a study by Vijayendra et al combination therapy of vasodilators, steroids and antivirals has given improvement in $79.4 \% .{ }^{4}$ Here in our study, if they lost to follow up patient is excluded, we have a recovery rate of $100 \%$, hence we promote use of multidrug regime for the effective treatment of SSNHL.

Limitations of our study include a small number of cases and hence we suggest a bigger scale to analyse the efficacy of the multi-drug treatment.

\section{CONCLUSION}

Our study shows that a multi-drug treatment of SSNHL can be much more effective than a single drug treatment. We report a $100 \%$ recovery out of which $50 \%$ had complete and $50 \%$ had partial recovery, after excluding the patient who was lost to follow up. We also conclude that using ITSI shows a greater improvement as seen in the case of bilateral SSNHL. We suggest the use of ITSI with oral steroids as the primary therapy along with adjuvant therapy using rheologiocal agents, neuro vitamins and antiplatelets; starting within 72 hours of symptoms for a better recovery.
Funding: No funding sources

Conflict of interest: None declared

Ethical approval: Not required

\section{REFERENCES}

1. Lee JB, Choi SJ, Park K, Park HY, Choo OS, Choung YH. The efficiency of intratympanic dexamethasone injection as a sequential treatment after initial systemic steroid therapy for sudden sensorineural hearing loss. Eur Arch Otorhinolaryngol. 2011;268(6):833-9.

2. Singh A, Kumar Irugu DV. Sudden sensorineural hearing loss-A contemporary review of management issues. J Otol. 2020;15(2):67-73.

3. Gupta V, Jain A, Banerjee PK, Rathi S. Sudden sensorineural hearing loss in adults: Our experience with multidrug high dose steroid regimen at tertiary care hospital. Indian J Otol. 2016;22:35-9.

4. Vijayendra H, Buggaveeti G, Parikh B, Sangitha R. Sudden sensorineural hearing loss: an otologic emergency. Indian J Otolaryngol Head Neck Surg. 2012;64(1):1-4.

5. Ho HG, Lin HC, Shu MT, Yang CC, Tsai HT. Effectiveness of intratympanic dexamethasone injection in sudden-deafness patients as salvage treatment. Laryngoscope. 2004;114(7):1184-9.

6. Park KH, Lee CK, Lee JD, Park MK, Lee BD. Combination therapy with systemic steroids, an antiviral agent, anticoagulants, and stellate ganglion block for treatment of sudden sensorineural hearing loss. Korean J Audiol. 2012;16(2):71-4.

7. Wijck VF, Staecher H, Lefebvre PP. Tropical steroid therapy using the Silverstein Microwick TM in sudden sensorineural hearing loss after failure of conventional treatment. Acta Oto-laryngologica. 2007;127:1012-7.

8. Lee JD, Park MK, Lee CK, Park KH, Lee BD. Intratympanic steroids in severe to profound sudden sensorineural hearing loss as salvage treatment. Clin Exp Otorhinolaryngol. 2010;3(3):122-5.

9. Stachler RJ, Chandrasekhar SS, Archer SM, Rosenfeld RM, Schwartz SR, Barrs DM et al. Clinical practice guideline: sudden hearing loss. Otolaryngol Head Neck Surg. 2012;146(3):S1-35.

10. Byl FM Jr. Sudden hearing loss: eight years' experience and suggested prognostic table. Laryngoscope. 1984;94(5 Pt 1):647-61.

11. Bullo F, Tzamtzis S, Tirelli G. Update on sudden hearing loss. Indian J Otol. 2013;19:95-9.

12. Battaglia A, Burchette R, Cueva R. Combination therapy (intratympanic dexamethasone+high-dose prednisone taper) for the treatment of idiopathic sudden sensorineural hearing loss. Otol Neurotol. 2008;29(4):453-60.

Cite this article as: Muniraju M, Killera S, Kauser S. A polydrug regime for treatment of sudden sensorineural hearing loss. Int J Otorhinolaryngol Head Neck Surg 2020;6:2275-8. 